\title{
Who wants to be a general psychiatrist?
}

When I was appointed to my consultant post nearly 10 years ago I was one of several able candidates. This was the culmination of many years' hard work and I was proud to be working at an inner-city teaching hospital, one where I had trained as a medical student. This was probably the last time that my department was fully staffed, with each year since bringing more challenges. In recent years only one of the specialist registrars I have trained has continued with general psychiatry, with the attractions of old age, liaison and forensic psychiatry seemingly unassailable. My confidence finally reached rock bottom when a senior house officer announced that she no longer wished to continue in psychiatry because the role models we (consultants) set were unattractive. Apparently the image we project is of long hours, unlimited demands, endless risks and little time to practise the art of psychiatry. With the anniversary of my appointment approaching now it seems appropriate to consider why my hard fought for job has all the attractions of the plague.

\section{Specialism}

Recent years have seen the proliferation of specialities within psychiatry. And if not a speciality, then a special interest. I am not quite sure where this leaves general psychiatry but it gives the impression of a second class subject. The creation of specialities often brings extra resources. These then become ring-fenced, with expanding empires of professionals gatekeeping access to the experts. Such services are able to advertise their expertise and set out parameters of engagement with the default option invariably being general psychiatry. That is to say, if there is a waiting-list, or the patient is too difficult or too risky, then he or she reverts to the domain of the general psychiatrist. Personality disorders are a good case in point. Whatever opinion a clinician may have regarding treatability or suitability, personality disorders inevitably present through general psychiatry. A number of new speciality services are now developing and many psychotherapy departments will say that the diagnosis of personality disorder is the most prevalent among their patients. Yet the specialities will only engage the patients on their service's terms, they are able to pick and choose who passes through the door and leave those with the most immediate and severe challenges to the generalist. This issue is particularly relevant to my service after recent experience managing patients with borderline personality disorders. We have developed considerable skills in this area, and are available at all hours and in all circumstances. Yet there is a belief that we are not expert. There are subtle and occasionally overt pressures at work, which undermine our confidence. These pressures can vary from the proliferation of private sector services (usually of unknown quality and evidence base) to hostile and ill-informed media coverage. Nevertheless our service continues to contain and support many people where other services fear to tread.

The same may also be true for the other specialities. For example, I have treated adolescents where other services were unable to respond, dangerous individuals at the request of the courts, patients with complex addiction problems, etc. There seems to be an endless demand for our services despite their apparent lack of esteem. Which brings me to my next point, the lack of control over access to our services.

\section{Gatekeeping}

One problem of not being a speciality is that we do what everyone else does not want to do. We are the default option, with boundaries becoming ever more blurred and expansive. A patient with acute alcohol withdrawal syndrome is deemed a psychiatric problem, not a medical one. Behaviourally and intellectually challenged people find themselves in casualty as an emergency 'mental health issue'. The disintegrating inner-city, with its complex mix of social, racial and drug and alcohol issues presents overwhelming challenges to the health and social services, with general psychiatry frequently being the stop gap. Over the past 10 years the expectations of the population from the health services have been considerably and appropriately raised, and general psychiatry is often in the spotlight. Yet frequently we are powerless in the face of overwhelming odds, and many times have little mandate to intervene. We are too often caught between distressed individuals and statutory bodies, all desperate that something should be done. The resulting pressure is felt by all professionals within the service. Increased bed occupancy, crowded clinics, high 
patient to keyworker ratios and their associated and welldocumented problems all testify to this. I am continually impressed by the ability of our service to absorb all these pressures, whereas speciality services can claim that their case-loads are full and that to take more patients would breach service standards. When further analysed it leads to a number of interesting questions, some of which may have a bearing on why the job is becoming so unpleasant. This was reinforced one morning while driving to my Tuesday clinic (18 follow-ups and two new patients, the majority on level 2 Care Programme Approach (CPA)) when I heard the President of the Royal College of Surgeons on the radio discussing the lack of resources for cardiothoracic surgery. He told the reporter that patients were dying on the waiting-list, lives that could possibly be saved if there was a more timely intervention. General psychiatry is allowed no such latitude. Every patient needs a timely risk assessment, and all risks must be covered. If something untoward happens then the service will be pilloried in the media and subject to various enquiries. Despite the now familiar reassurances that this is a learning process to improve the service, it somehow does not feel like it.

I am left wondering how general psychiatry reached such a position. Why, like the surgeon, are we not able to say 'yes, I can help this person', but 'I cannot do so unless I am given sufficient resources'? This in part must reflect deficiencies in our training and the confidence it gives us in understanding our role in the multi-disciplinary team and mixed economy health system.

\section{Training}

In training sessions with my specialist registrars I frequently liken my role to that of a managing director in a small company. Our sectorised service has ongoing care programme commitments to over 400 patients in addition to receiving over 400 new referrals per year, not to mention the busy in-patient unit. The team includes highly skilled professionals from a variety of disciplines in addition to support workers and representatives from nonstatutory organisations. These clinicians frequently have greater skills in their individual areas than I do. It is my belief that the consultant does not have the natural right to lead this team. The right has to be earned through acquired clinical, managerial and interpersonal skills. These skills include the ability to juggle inadequate resources while prioritising risks, carrying your own and the team's anxieties when making decisions with insufficient information and understanding the Byzantine structures of the care system so as to maximise resources in addition to the usual continuing professional development (CPD) and clinical governance issues. The training schemes appear to be inadequate to prepare doctors for such a task. All too soon doctors reach the end of the training period and not surprisingly they find the option of innercity psychiatry singularly unappealing.

\section{What is to be done?}

General psychiatry needs to reinvent itself, never more so than in the inner-cities. Its status as a speciality in its own right needs to be reinforced, rather than it being seen as something that all psychiatrists do before specialising in something else. There needs to be a comprehensively defined syllabus for higher training identifying core skills and areas of expertise in addition to the skills of interagency working and team leadership. The consultant needs to be equally adept working with the community mental health team and in the in-patient environment.

The in-patient unit needs recognition as the high value added end of the business, not something that is persistently denigrated and undermined. It should be a highly resourced and skilled environment. This unit is the necessary foundation of a successful and confident community service.

The job plan and indeed the work structure needs to be completely overhauled. Consultant posts seem to have evolved organically over the past half century without any strategic overview or consideration of other developments in treatments and service structures; at least none are apparent in many places I have visited. The College should devise realistic but ambitious model job plans that would sustain consultants in difficult working environments. It is my view that in the inner-cities at least we need to double the number of consultants, possibly even going as far as our old age colleagues to recommend one post per 10000 people.

Consultants should not work in isolation from their medical colleagues. Chance meetings in stairwells and car parks are not good enough. We should be grouped in twos or threes, with weekly meetings to discuss difficult cases and to benchmark care. This is even more important in dispersed and professionally isolated community settings. The working week should be subdivided into planned events, i.e. ward rounds, team meetings, CPA reviews, CPD sessions, etc. These need to be protected from the emergency workload facilitated by consultant team working. This would also allow us to develop other interests away from base duties, which would make the job more sustainable and may even allow us to compete with our specialist colleagues on the national awards campaign. Too often the jobbing general psychiatrist is absent from the table when service specifications are devised, or strategic training issues are discussed. We need to become a good deal more militant and, like the cardiothoracic surgeons, identify good quality care and refuse to compromise our standards. We know what works and it is not difficult to spell out the cost!

There remains the potential for the job to be both challenging and enjoyable. However, unless there is an urgent initiative, charged with considerable additional resources, the decline will continue.

Finally, I think we should mark the fight back by renaming ourselves. Adult general psychiatry does not seem to do justice to the job. May I begin the process by suggesting something like emergency and community psychiatry, but I feel sure that my colleagues will be able to improve on this!

Stephen Colgan Consultant General Psychiatrist, Meadow Brook, Hope Hospital, Salford M6 8HG 